University of Wollongong

Research Online

Faculty of Engineering and Information

Faculty of Engineering and Information

Sciences - Papers: Part A

Sciences

$1-1-2013$

EBSD observations of recrystallisation and tensile deformation in twinning induced plasticity steel

Ahmed A. Saleh

University of Wollongong, asaleh@uow.edu.au

Azdiar A. Gazder

University of Wollongong, azdiar@uow.edu.au

Elena Pereloma

University of Wollongong, elenap@uow.edu.au

Follow this and additional works at: https://ro.uow.edu.au/eispapers

Part of the Engineering Commons, and the Science and Technology Studies Commons

Research Online is the open access institutional repository for the University of Wollongong. For further information contact the UOW Library: research-pubs@uow.edu.au 


\title{
EBSD observations of recrystallisation and tensile deformation in twinning induced plasticity steel
}

\begin{abstract}
The microstructure evolution of cold-rolled and isochronally annealed Fe-24Mn-3Al-2Si-1Ni-0.06C twinning induced plasticity steel was investigated by electron back-scattering diffraction (EBSD). Deformation behaviour of a fully recrystallised sample was tracked in a selected area as a function of the true strain using a combination of interrupted tensile testing and EBSD. The results show that the cold rolled microstructure contained a large fraction of primary and secondary twins as well as remnants of annealing twins carried over from the prior hot rolling stage. A novel deconstruction technique was applied to a partially recrystallised sample in order to separate the microstructure into deformed, recovered, newly nucleated and growing recrystallised grains. The interrupted tensile tests revealed the formation of fine striations in grains with "111" "111" and " 110 " orientations just after yielding. While the striations could be attributed to either stacking faults or the formation of fine twin packets, some of them manifested as twin boundaries as the true strain was increased up to 0.209. 2013 Indian Institute of Metals.
\end{abstract}

\section{Keywords}

tensile, deformation, twinning, recrystallisation, induced, observations, plasticity, steel, ebsd

Disciplines

Engineering | Science and Technology Studies

\section{Publication Details}

Saleh, A. A., Gazder, A. A. \& Pereloma, E. (2013). EBSD observations of recrystallisation and tensile deformation in twinning induced plasticity steel. Transactions of the Indian Institute of Metals, 66 (5-6), 621-629. 
Saleh et al., EBSD OBSERVATIONS OF RECRYSTALLISATION AND TENSILE DEFORMATION IN TWIP STEEL

\title{
EBSD OBSERVATIONS OF RECRYSTALLISATION AND TENSILE DEFORMATION IN TWINNING INDUCED PLASTICITY STEEL
}

\author{
Ahmed A. Saleh"1, Azdiar A. Gazder1, 2, Elena V. Pereloma1, 2 \\ ${ }^{1}$ School of Mechanical, Materials and Mechatronic Engineering, University of \\ Wollongong, New South Wales 2522, Australia \\ 2Electron Microscopy Centre, University of Wollongong, New South Wales 2519, \\ Australia
}

\begin{abstract}
The microstructure evolution of cold-rolled and isochronally annealed Fe-24Mn3Al-2Si-1Ni-0.06C twinning induced plasticity steel was investigated by electron back-scattering diffraction (EBSD). Deformation behaviour of a fully recrystallised sample was tracked in a selected area as a function of the true strain using a combination of interrupted tensile testing and EBSD. The results show that the cold rolled microstructure contained a large fraction of primary and secondary twins as well as remnants of annealing twins carried over from the prior hot rolling stage. A novel deconstruction technique was applied to a partially recrystallised sample in order to separate the microstructure into deformed, recovered, newly nucleated and growing recrystallised grains. The interrupted tensile tests revealed the formation of fine striations in grains with $\langle 111\rangle$ and $\langle 110\rangle$ orientations just after yielding. While the striations could be attributed to either stacking faults or the formation of fine twin packets, some of them manifested as twin boundaries as the true strain was increased up to 0.209 .
\end{abstract}




\section{INTRODUCTION}

Increasing demand for economical and environment-friendly cars through reduced weight and $\mathrm{CO}_{2}$ emissions has stimulated the development of newer advanced high strength steels. Austenitic TWinning Induced Plasticity (TWIP) steels with high Mn content (23-35 wt.\%) and additions of $\mathrm{Al}$ (3-4 wt.\%) and Si (1-3 wt.\%) possess low stacking fault energy $\left(18-40 \mathrm{~mJ} / \mathrm{m}^{2}\right)$ which causes concurrent slip and twinning during plastic deformation ${ }^{1-4}$. The operation of these two deformation accommodation mechanisms leads to high strain hardening rates and results in excellent combinations of ultimate tensile strength (600-1100 $\mathrm{MPa}$ ) and total elongation $(>50 \%)^{1-2}$. Understanding how TWIP steel microstructures: (1) undergo annealing after cold-rolling or (2) accommodate deformation after full recrystallisation enables the optimisation of their production/processing parameters in order to tailor them to return a particular combination of mechanical properties. For example, fine grained microstructures in TWIP steels obtained either by significant rolling reductions or by a decrease in the annealing temperature results in high strengths while maintaining acceptable ductility levels ${ }^{5-6}$. On the other hand, the preservation of the deformed, nano-twinned structure along with a reduced total dislocation density due to recovery -type heat treatments produces an even better combination of strength and ductility ${ }^{7}$.

To-date, detailed investigations of the microstructure evolution during the recrystallisation of cold rolled TWIP steels are limited ${ }^{8-12}$. There are also very few studies that detail the exact changes occurring during the deformation of fully recrystallised TWIP microstructures ${ }^{4}$ 13-15. Although some work on the 
Saleh et al., EBSD OBSERVATIONS OF RECRYSTALLISATION AND TENSILE DEFORMATION IN TWIP STEEL

deformation behaviour of TWIP steels has been carried out using in-situ diffraction measurements ${ }^{16-17}$, the observation of their microstructure evolution during straining is typically limited to ex-situ examinations of various samples and different areas ${ }^{4,13-15}$.

To this end, the present work extensively employs the Electron Back-Scattering Diffraction (EBSD) technique to track microstructure evolution in TWIP steel during: (i) isochronal annealing after cold-rolling to $42 \%$ thickness reduction, and (ii) uniaxial tensile loading of a fully recrystallised sample in a selected area of interest.

\section{EXPERIMENTAL AND ANALYTICAL PROCEDURE}

An as-cast TWIP steel slab with the nominal composition $24 \mathrm{Mn}-3 \mathrm{Al}-2 \mathrm{Si}-1 \mathrm{Ni}-$ 0.06C wt.\% was homogenised at $1100{ }^{\circ} \mathrm{C}$ for $2 \mathrm{~h}$, hot rolled to $52 \%$ thickness reduction at the same temperature in 4 passes at $\sim 17 \%$ reduction per pass then cold rolled to $42 \%$ thickness reduction (equivalent to a true strain of 0.55 ) in 11 passes at $\sim 4.8 \%$ reduction per pass. $30 \times 10 \times 7.3 \mathrm{~mm}^{3}$ samples were cut from the cold-rolled strip and subjected to isochronal annealing between 600 and $850{ }^{\circ} \mathrm{C}$ which included $240 \mathrm{~s}$ of heating to stable temperature and $300 \mathrm{~s}$ of soaking time followed by immediate water quenching. Vickers microhardness with a $500 \mathrm{~g}$ load was used to estimate the fraction softened as a function of the isochronal annealing temperature.

All EBSD mapping was undertaken on a JEOL-JSM7001F field emission gun scanning electron microscope fitted with a Nordlys-II(S) camera and the Oxford 
Saleh et al., EBSD OBSERVATIONS OF RECRYSTALLISATION AND TENSILE DEFORMATION IN TWIP STEEL

Instruments AZtec software suite operating at $15 \mathrm{kV}, \sim 2-5 \mathrm{nA}$ and $15 \mathrm{~mm}$ working distance. Microstructure characterisation of the isochronally annealed samples was conducted on the rolling direction (RD) - normal direction (ND) plane of the samples in the middle of the sample cross-sectional thickness. Step sizes of 0.05 and $0.4 \mu \mathrm{m}$ were used for the cold rolled sample in order to acquire selected and large area statistics, respectively. While a step size of $0.125 \mu \mathrm{m}$ was used for the $600{ }^{\circ} \mathrm{C}$ sample, a step size of $0.175 \mu \mathrm{m}$ was manintained constant for all other partially recrystallised conditions.

Post-processing of the EBSD maps was carried out using the HKL Channel-5 software package. Low-angle grain boundaries (LAGBs) and high-angle boundaries (HAGBs) possess misorientations between $2^{\circ} \leq \theta<15^{\circ}$ and $15^{\circ} \leq \theta \leq 57.5^{\circ}$ respectively. The total high angle grain boundary (THAGBs, $15^{\circ} \leq \theta \leq 62.5^{\circ}$ ) population comprises HAGBs and twin boundaries (TBs). The twin boundaries consist of first order $\left(\Sigma 3=60^{\circ}\langle 111\rangle\right)$ and second order $\left(\Sigma 9=38.9^{\circ}\langle 101\rangle\right)$ TBs.

The partially recrystallised EBSD map for the $700{ }^{\circ} \mathrm{C}$ condition was deconstructed into subsets comprising deformed, recovered, newly nucleated and growing recrystallised grains in accordance with the methodology described in Ref. 18. In brief, the unrecrystallised and recrystallised fractions were first separated using a grain orientation spread (GOS) threshold $\left(\theta_{C}\right)$ of $1.5^{\circ}$. Then the unrecrystallised fraction was further sub-divided into deformed and recovered subsets by applying an internal misorientation threshold of $7^{\circ}$. Lastly, the recrystallised fraction was sub-divided into newly nucleated and growing recrystallised grains by applying a threshold based on the arithmetic mean of the frequency distribution of the 
Saleh et al., EBSD OBSERVATIONS OF RECRYSTALLISATION AND TENSILE DEFORMATION IN TWIP STEEL

recrystallised grain size. The latter accounts for the increasing (sub)grain size with higher isochronal annealing temperature.

To study the deformation behaviour, a flat dog-bone shaped tensile sample of 25 $\mathrm{mm}$ gage length and $5 \mathrm{~mm}$ width was wire-cut from the $850^{\circ} \mathrm{C}$, fully recrystallised material such that its gage length and width were parallel to the rolling (RD) and the transverse (TD) directions, respectively. Uniaxial tensile testing was undertaken on an in-house modified $5 \mathrm{kN}$ Kammerath \& Weiss tensile stage operating in speed control mode at $5 \mu \mathrm{m} / \mathrm{s}$. The tension test was interrupted at predetermined load levels and the EBSD mapping was conducted on a defined area of interest in the middle of the gage length at a constant step size of $0.1 \mu \mathrm{m}$.

\section{RESULTS AND DISCUSSION}

\subsection{Effect of isochronal annealing}

The change in microhardness as a function of the isochronal annealing temperature and the area fractions softened and recrystallised estimated from microhardness and EBSD measurements, respectively are shown in Fig. 1. Representative inverse pole figure (IPF) maps of the cold-rolled and partially recrystallised microstructures aligned with the horizontal RD are depicted in Fig. 2.

The microstructure of the cold-rolled sample comprises elongated grains along the RD (Fig. 2a) where the imposed strain was accommodated inhomogeneously via various deformation modes. Some grains are free of twins and deformed via slip only, whereas others contain twins and in some instances, microscopic shear bands (as indicated by the arrows in Fig. 2a(inset)). The deformation twins are 
present either as parallel primary twins occasionally rotated towards RD or as intersecting arrangements of primary and secondary twins. In addition, some coarse annealing twins carried over from prior hot rolling are also detected.

The $600{ }^{\circ} \mathrm{C}$ sample (Fig. $2 \mathrm{~b}$ ) recorded $\sim 16 \%$ softening from the microhardness measurements and $\sim 3 \%$ recrystallisation from the EBSD maps. The discrepancy in the above values is due to recovery processes involving the rearrangement of the dislocation substructures (carried over from cold-rolling) resulting in an overall reduction of the total accumulated stored energy ${ }^{19}$. Thereafter, the process of recrystallisation proceeds rapidly with an $\sim 68 \%$ fraction softened obtained at $700^{\circ} \mathrm{C}$ (Fig. 2c). The relatively fast recrystallisation kinetics up to this stage of annealing is similar to that encountered in other TWIP steels9.

The start of recrystallisation in the $600^{\circ} \mathrm{C}$ sample is associated with the bulging of annealing twins at grain boundaries (Figs. $2 \mathrm{~b}$ and $3 \mathrm{a}$ ). Similar twin bulging events were seen during the recovery stage in two moderately cold rolled austenitic stainless steels ${ }^{20}$. Twin bulges at grain boundaries and the formation of nuclei with orientations either close to or twin related to the cold-rolled matrix are also found in the $700^{\circ} \mathrm{C}$ sample (Fig. $2 \mathrm{c}$ and $3 \mathrm{~b}$ ). In relation to the twin-related nuclei, it was suggested that they initially nucleate with orientations close to that of the deformed matrix and then twinning proliferates in order to form HAGBs with the matrix ${ }^{21}$. While observing similar nucleation events during the recrystallisation of a $97 \%$ cold rolled bronze $(\mathrm{Cu}-10 \mathrm{Sn})$, Peters $^{22}$ proposed that the first nuclei form by polygonisation with orientations close to the deformed matrix; subsequent to which, first and second order twinning takes place. 
Saleh et al., EBSD OBSERVATIONS OF RECRYSTALLISATION AND TENSILE DEFORMATION IN TWIP STEEL

Following the above, the progress of recrystallisation tends to continue slightly more sluggishly; reaching an $\sim 83 \%$ fraction recrystallised at $750^{\circ} \mathrm{C}$ and a $96 \%$ fraction recrystallised at $850^{\circ} \mathrm{C}$ (Figs. 2d-f). If TBs are disregarded as grain boundaries, the equivalent circle diameter -based average recrystallised grain size increases from $3.6 \pm 2.7 \mu \mathrm{m}$ at $700^{\circ} \mathrm{C}$ to $\sim 7.9 \mu \mathrm{m}$ at $850^{\circ} \mathrm{C}$ (Table 1 ). However, the grain refining effect of annealing twins is highlighted by the fact that when TBs are considered as grain boundaries, the average recrystallised grain size reduces by as much as $1.7 \pm 0.2$ times.

The effect of isochronal annealing temperature on the misorientation distribution is shown in Fig. 3c and the average misorientation and the various boundary area fractions are summarised in Table 1. The cold-rolled microstructure is dominated by LAGBs along with minor fractions of HAGBs and TBs. The nucleation events seen in the $600{ }^{\circ} \mathrm{C}$ and $700{ }^{\circ} \mathrm{C}$ samples (Figs. 3a and 3b) and the concurrent grain growth seen in Figs. $2 \mathrm{~b}$-f leads to increases in the $\Sigma 3$ and $\Sigma 9$ area fractions (first and second order TBs, respectively) up to the $750{ }^{\circ} \mathrm{C}$ sample. Up to this point, the relatively low fraction of $\Sigma 9$ boundaries compared to $\Sigma 3^{11}$ can be attributed to the limited impingement of $\Sigma 3$ boundaries leading to $\Sigma 9$ formation via the twinning reaction ${ }^{23}: \Sigma 3+\Sigma 3 \rightarrow \Sigma 9$. Thereafter, the decrease in the $\Sigma 9$ boundary area fraction towards the end of recrystallisation process $\left(775\right.$ and $850{ }^{\circ} \mathrm{C}$ ) conforms with the " $\Sigma 3$ regeneration model" proposed by Randle ${ }^{23}$ which postulates the twinning reaction: $\Sigma 3+\Sigma 9 \rightarrow \Sigma 3$.

The unrecrystallised (deformed and recovered) and recrystallised (newly nucleated and growing grain) fractions of the partially recrystallised $700^{\circ} \mathrm{C}$ sample are shown in Figs. 4a-d. Their corresponding misorientation distributions are 
given in Fig. 4e. While the unrecrystallised fraction is dominated by LAGBs, the recovered grains have an expectedly lower fraction of LAGBs compared to the deformed grains as the recovered grains possess lower internal misorientations due to the dislocation annihilation upon annealing.

The fraction of first order $\Sigma 3$ TBs is the lowest in the deformed grains, is higher in recovered grains, is the highest in the newly nucleated grains and then reduces again in the growing grain fraction. On the other hand, the fraction of second order $\Sigma 9$ TBs are more pronounced in the recrystallised fractions than the unrecrystallised fractions. The lower $\Sigma 3$ TB population in the growing grain fractions as opposed to their newly nucleated counterparts follows Gindraux and Form ${ }^{24}$ where annealing twins proliferate to reorient the grain boundaries in order to facilitate dislocation absorption and mobility during the initial stages of recrystallisation. Here, twinning contributes significantly to the overall reduction in stored energy during nucleation. Thereafter, during the grain growth stage, the previously formed twins are annihilated and a relatively limited evolution of newer twins occurs.

The growth kinetics in TWIP steel can be explained by examining the grain boundary character at the common interface between the newly nucleated and unrecrystallised fractions via subset double-dilation 18 for the 700,750 and $775{ }^{\circ} \mathrm{C}$ samples (Fig. 4f). The low-mobility LAGBs and TBs together constitute 59\%, 41\% and $47 \%$ of the total interface boundary population at 700,750 and $775{ }^{\circ} \mathrm{C}$, respectively. It suggests that orientation-dependent, stored energy considerations have a dominant role in dictating the evolution of the microstructure during the recrystallisation process ${ }^{12}$. Thus, newly nucleated grains with orientations that 
inherently possess locally higher stored energies will have a growth advantage in order to maximise the release of the stored energy carried over from cold rolling25.

\subsection{Effect of uniaxial tension}

The true stress versus strain curve of the $850{ }^{\circ} \mathrm{C}$, fully recrystallised sample is given in Fig. 5. The red circles in this figure correspond to true strains of 0, 0.0014, $0.023,0.072$, and 0.209 and are the points where the tensile test was interrupted for EBSD measurements. The microstructure evolution of the selected area with increasing tensile strain is shown in Fig. 6 via IPF maps. Similar to Fig. $2 \mathrm{f}$ and the discussion of its microstructure in Section 3.1, the initial recrystallised microstructure comprises equiaxed grains with a high fraction of annealing twin $\Sigma 3$ boundaries (Fig. 6a, Table 2).

Expectedly, no change in the microstructure is detected at a true strain of 0.0014 (cf. Figs. 6a and 6b) since it corresponds to a stress of $\sim 210 \mathrm{MPa}$ which is lower than the macro-yielding point at $\sim 290 \mathrm{MPa}$. At a true strain of 0.0023 , striations in the form of single lines or parallel packets evolve preferentially in grains with oreinations close to $\langle 111\rangle$ and $\langle 110\rangle$ (Fig. 6c). These striations originate mostly at the grain and twin boundaries, while in fewer instances they start and finish within a grain. Intersecting striations were also detected in a few grains as shown by the white circle in Fig. 6c.

The number of striations increases progressively upon straining to 0.072 and 0.209 with some of them being indexed as deformation twin boundaries (indicated by the black arrows in Figs. 6d and e). Due to the limitations of the EBSD technique 
Saleh et al., EBSD OBSERVATIONS OF RECRYSTALLISATION AND TENSILE DEFORMATION IN TWIP STEEL

in general and the adopted experimental methodology in particular, there are two possibilities related to the provenance of these striations.

As pointed out in previous studies ${ }^{4}$, since the thickness of deformation twins at low strain levels is in the order of tens of nanometres, they cannot be crystallographically detected due to the limited spatial resolution of the EBSD technique. With increasing strain, the twinning activity increases such that the twins stack into relatively thick bundles which are eventually detectable by EBSD. Alternatively, TEM investigations of low stacking fault energy austenitic steels during the early stages of deformation have frequently reported the formation of stacking faults. Stacking faults were recently observed in the austenite grains of transformation induced plasticity steel at a tensile strain of $0.005^{26}$. Prior to the observation of deformation twinning, stacking faults in the form of widely separated partial dislocations or as long and narrow straight striations have also been detected in a Fe-18Mn-0.6C-1.5Al TWIP steel at a tensile strain of 0.0415 . As opposed to other EBSD studies on TWIP steel deformation behaviour ${ }^{4}$, the present work tracks the evolution of the same set of grains up to 0.209 true strain. This enables the observation of the change in the nature of the striations; from initial lines of high band contrast at 0.023 true strain to their identification as twin boundaries from 0.072 true strain onwards. Thus, rather than interpreting the striations as thin, unindexed twins, it is more probable that they are stacking faults that form preferentially at the grain and twin boundaries (Fig. 6c). Consequently, and as proposed by Byun ${ }^{27}$, the divergence of the dissociated partial dislocations to an infinite separation distance with increasing tensile strain leads to twin formation. 
Saleh et al., EBSD OBSERVATIONS OF RECRYSTALLISATION AND TENSILE DEFORMATION IN TWIP STEEL

The black areas in Figs. 6d and 6e depict unindexed regions in the EBSD maps due to the increase in the surface roughness of the sample via the orange-peel effect which is a manifestation of the anisotropic nature of plastic strain within individual grains ${ }^{28}$. Additionally, and with increasing tensile strain, grains start popping out of the plane of the tensile sample surface forming peaks and valleys; which indicates that a significant part of the strain is accommodated at the grain boundaries.

The change in the grain boundary area fraction with increasing tensile strain is given in Table 2. The area fraction of LAGBs continues to increase and is associated with a concurrent decrease in the HAGBs and $\Sigma 3$ TBs population.

Since both annealing and deformation twin boundaries follow the same $\Sigma 3=60^{\circ}$ $\langle 111\rangle$ relationship, it is not possible to distinguish between them on the basis of misorientation or crystallography. However, the main advantage of observing the same area while a sample undergoes uniaxial tension is that it also allows us to track the evolution of the annealing twins at different strains. As illustrated by the white ovals in Figs. $6 \mathrm{~d}$ and 6e, the annealing twin boundaries at 0.023 and 0.072 strain are later identified as regular HAGBs at a tensile strain of 0.209 (Fig. 6e). This decay of the annealing twin boundaries is due to the local lattice rotation at the sides of the TBs leading to a deviation from the exact $60^{\circ}\langle 111\rangle$ relationship ${ }^{29}$. This deviation increases with greater tensile strain until it exceeds the employed tolerance limit of $6^{\circ}$ (following the Palumbo-Aust criterion). Hence, such boundaries are no longer identified as TBs but are rather recognised as being regular HAGBs. Accordingly, and despite the evolution of deformation twins, the area fraction of TBs generally decreases with increasing tensile strain. An 
additional reason for the diminishing twin boundary fraction is the masking effect associated with the increasing area fraction of LAGBs (Table 2).

Lastly, an example detailing the effect of deformation twinning is discussed. The orientations of twin-free and twinned grains at a tensile strain of 0.209 are shown on the IPF in Fig. 6f as clear black and solid red squares, respectively. The dashed black line on the IPF (Fig. 6f) indicates the area where the Schmid factors for slip and twinning are equal. Thus the area to the left of the dashed line denote orientations with higher Schmid factors that favour slip while the region to the right of the dashed line comprise orientations with higher Schmid factors that favour twinning. In this regard, Fig. $6 \mathrm{f}$ clearly shows some twinned grains (solid red squares) falling to the left of the dashed black line and within the region that favours slip. This observation is in agreement with previous investigations that correlate twinning activity with the crystallographic orientations of TWIP steels ${ }^{13 \text {, }}$ 14. Gutierrez-Urrutia et al. ${ }^{14}$ suggested that while the orientation dependence of twinning follows Schmid's law at low strains, it increasingly deviates away from it with greater accumulated strain. They ascribed the deviation to the local stress concentration effect which is induced by the interaction with neighbouring grains. On the other hand, we postulate that the presumed deviation from Schmid's law at higher tensile strains is the result of the increased feasibility of twin nucleation via extrinsic stacking faults in orientations with low Schmid factors for twinning ${ }^{30}$.

\section{CONCLUSIONS}

The application of EBSD allows for detailed insights into the evolution of the microstructure in TWIP steel during isochronal annealing and uniaxial tensile 
loading. The strain imposed during cold rolling to $42 \%$ thickness reduction was accommodated via various deformation mechanisms including slip, twinning and micro-shear banding. From the early stages of recrystallisation, annealing twins contribute to nucleation events as twin bulges and twin-related nuclei. The subsequent growth of the newly nucleated grains is affected by orientationdependent, stored energy considerations as well as second-order twinning.

During the early stages of uniaxial tensile loading, the presumed formation of stacking faults were observed as striations in grains with orientations close to $\langle 111\rangle$ and $\langle 110\rangle$. With increasing tensile strain, some of these striations were successfully indexed as twin boundaries. The area fraction of annealing twin boundaries decreases with greater tensile strain due to local lattice rotation effects which lead to a deviation from the exact $60^{\circ}\langle 111\rangle$ relationship. The deviation from Schmid's law with increasing tensile strain can be ascribed to the increased feasibility of twin nucleation via extrinsic faulting in grains that are nominally regarded as being unfavourably oriented for twinning.

\section{ACKNOWLEDGEMENTS}

The authors are grateful to Prof. D. B. Santos of the Federal University of Minas Gerais, Brazil for providing the source material. The authors acknowledge the use of the JEOL-JSM7001F FEG-SEM at the UOW Electron Microscopy Centre purchased with the financial support from the Australian Research Council (LE0882613). 
Saleh et al., EBSD OBSERVATIONS OF RECRYSTALLISATION AND TENSILE DEFORMATION IN TWIP STEEL

\section{REFERENCES}

1. Grassel O, Kruger L, Frommeyer G, Meyer L W, Int J Plast, 16 (2000) 1391.

2. Frommeyer G, Brüx U, Neumann P, ISIJ Int, 43 (2003) 438.

3. Vercammen S, Blanpain B, De Cooman B C, Wollant P, Acta Mater, 52 (2004) 2005.

4. Barbier D, Gey N, Allain S, Bozzolo N, Humbert M, Mater Sci Eng A, 500 (2009) 196.

5. Bouaziz O, Allain S, Scott C, Scr Mater, 58 (2008) 484.

6. Ueji R, Tsuchida N, Terada D, Tsuji N, Tanaka Y, Takemura A, Kunishige K, Scr Mater, 59 (2008) 963.

7. Bouaziz O, Scott C P, Petitgand G, Scr Mater, 60 (2009) 714.

8. Scott C, Allain S, Faral M, Guelton N, Rev Metall, 6 (2006) 293.

9. Bracke L, Verbeken K, Kestens L, Penning J, Acta Mater, 57 (2009) 1512.

10. Santos B D, Saleh A A, Gazder A A, Carman A, Duarte D M, Ribeiro É A S, Gonzalez B M, Pereloma E V, Mat Sci Eng A, 528 (2011) 3545.

11. Saleh A A, Gazder A A, Santos B D, Pereloma E V, Adv Mater Res, 409 (2012) 719.

12. Gazder A A, Saleh A A, Pereloma E V, Scr Mater, 65 (2011) 560.

13. Yang P, Xie Q, Meng L, Ding H, Tang Z, Scripta Mater, 55 (2006) 629.

14. Gutierrez-Urrutia I, Zaefferer S, Raabe D, Mat Sci Eng A, 527 (2010) 3552.

15. Beladi H, Timokhina I B, Estrin Y, Kim J, De Cooman B C, Kim S K, Acta Mater, 59 (2011) 7787.

16. Yan K, Carr D G, Callaghan M D, Liss K-D, Li H, Scr Mater, 62 (2010) 246. 
Saleh et al., EBSD OBSERVATIONS OF RECRYSTALLISATION AND TENSILE DEFORMATION IN TWIP STEEL

17. Saleh A A, Pereloma E V, Clausen B, Brown D W, Tomé C N, Gazder A A, Acta Materialia, In press (2013), DOI: 10.1016/j.actamat.2013.05.017.

18. Gazder A A, Sanchez-Araiza M, Jonas J J, Pereloma E V, Acta Mater, 59 (2011) 4847.

19. Humphreys F J, Hatherly M, Recrystallisation and Related Annealing Phenomena, 2nd ed., Elsevier, Oxford (2004).

20. Jones A R, J Mater Sci, 16 (1981) 1374.

21. Field D P, Bradford L T, Nowell M M, Lillo T M, Acta Mater, 55 (2007) 4233.

22. Peters B F, Met Trans, 4 (1973) 757.

23. Randle V, Acta Mater, 47 (1999) 4187.

24. Gindraux G, Form W, J Inst Met (London), 101 (1973) 85.

25. Sebald R, Gottstein G, Acta Mater, 50 (2002) 1587.

26. Rafaja D, Krbetschek C, Borisova D, Schreiber G, Klemm V, Thin Solid Films, 530 (2013) 105.

27. Byun T S, Acta Mater, 51 (2003) 3063.

28. Reed-Hill R E, Physical metallurgy principles, New York: D. Van Nostrand Company (1973).

29. Mishra S K, Tiwari S M, Kumar A M, Hector L G, Met Mat Trans A, 43 (2012) 1598.

30. Gazder A A, Saleh A A, Pereloma E V, Scr Mater, 68 (2013) 436. 


\section{$\underline{\text { Tables }}$}

Table 1. The change in the average recrystallised grain size, average misorientation $\left(\theta_{\mathrm{AVG}}{ }^{\circ}\right)$ and grain boundary area fraction with isochronal annealing temperature.

\begin{tabular}{|c|c|c|c|c|c|c|c|}
\hline \multirow{2}{*}{ Sample } & \multicolumn{2}{|c|}{$\begin{array}{l}\text { Recrytallised grain } \\
\text { size }(\mu \mathrm{m})\end{array}$} & \multirow{2}{*}{$\begin{array}{c}\text { Average } \\
\text { misorientation } \\
\left(\theta_{\mathrm{AVG}}{ }^{\circ}\right)\end{array}$} & \multicolumn{4}{|c|}{ Area fraction (\%) } \\
\hline & w/o TBs & with TBs & & LAGB & HAGB & $\Sigma 9 \mathrm{~TB}$ & $\Sigma 3$ TВ \\
\hline As-CR & - & - & 14.15 & $79.1 \pm 1.6$ & $9.4 \pm 0.2$ & $0.4 \pm 0.4$ & $11.5 \pm 2.2$ \\
\hline $600^{\circ} \mathrm{C}$ & - & - & 15.97 & $74.1 \pm 0.6$ & $11.4 \pm 1.1$ & $0.6 \pm 0.7$ & $14.6 \pm 2.5$ \\
\hline $700^{\circ} \mathrm{C}$ & $3.6 \pm 2.7$ & $2.1 \pm 1.4$ & 36.79 & $30.3 \pm 1.4$ & $34.9 \pm 0.3$ & $5.6 \pm 0.1$ & $34.8 \pm 2.4$ \\
\hline $750^{\circ} \mathrm{C}$ & $4.9 \pm 3.7$ & $2.7 \pm 1.8$ & 48.87 & $9.4 \pm 0.8$ & $48.1 \pm 0.5$ & $10.7 \pm 0.1$ & $42.5 \pm 2.1$ \\
\hline $775^{\circ} \mathrm{C}$ & $4.9 \pm 3.7$ & $2.7 \pm 2.0$ & 48.97 & $5.3 \pm 0.2$ & $47.0 \pm 0.7$ & $7.4 \pm 0.1$ & $47.7 \pm 1.7$ \\
\hline $850^{\circ} \mathrm{C}$ & $7.9 \pm 5.5$ & $4.4 \pm 3.0$ & 48.49 & $4.4 \pm 0.6$ & $50.2 \pm 0.6$ & 7. $1 \pm 0.2$ & $45.4 \pm 0.9$ \\
\hline
\end{tabular}

Table 2 . The change in the average misorientation $\left(\theta_{\mathrm{AVG}}{ }^{\circ}\right)$ and grain boundary area fraction with greater true strain during uniaxial tensile loading.

\begin{tabular}{c|c|c|c|c}
\hline \multirow{2}{*}{ Strain (\%) } & $\begin{array}{c}\text { Average misorientation } \\
\left(\boldsymbol{\theta}_{\text {AVG }}{ }^{\circ}\right)\end{array}$ & LAGB & HAGB & $\boldsymbol{\Sigma}$ A3 TB \\
\cline { 2 - 4 } & 49.76 & 2.18 & 48.19 & 49.64 \\
0.14 & 49.76 & 2.06 & 48.61 & 49.33 \\
2.3 & 48.02 & 4.73 & 48.77 & 46.5 \\
7.2 & 41.21 & 18.72 & 43.85 & 37.44 \\
20.9 & 22.77 & 59.4 & 22.21 & 18.39 \\
\hline
\end{tabular}




\section{Figures}

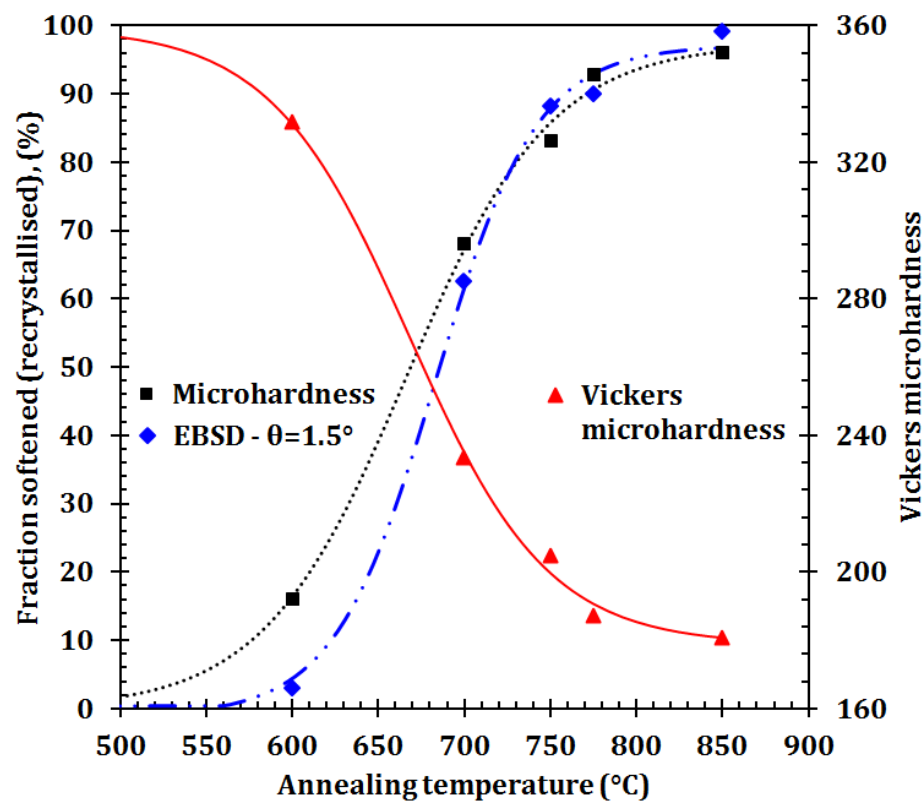

Figure 1. The evolution of the microhardness with higher isochronal annealing temperature and the fractions softened and recrystallised estimated by microhardness and EBSD, respectively. 


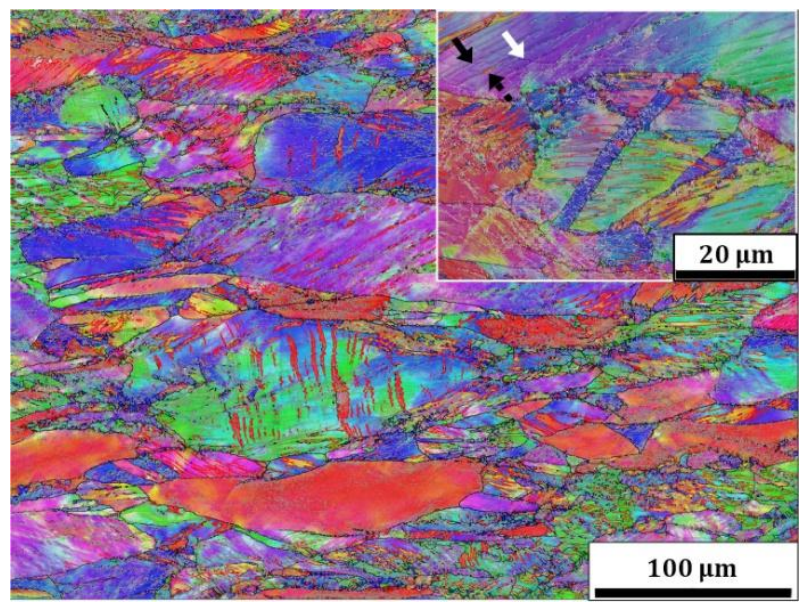

(a)

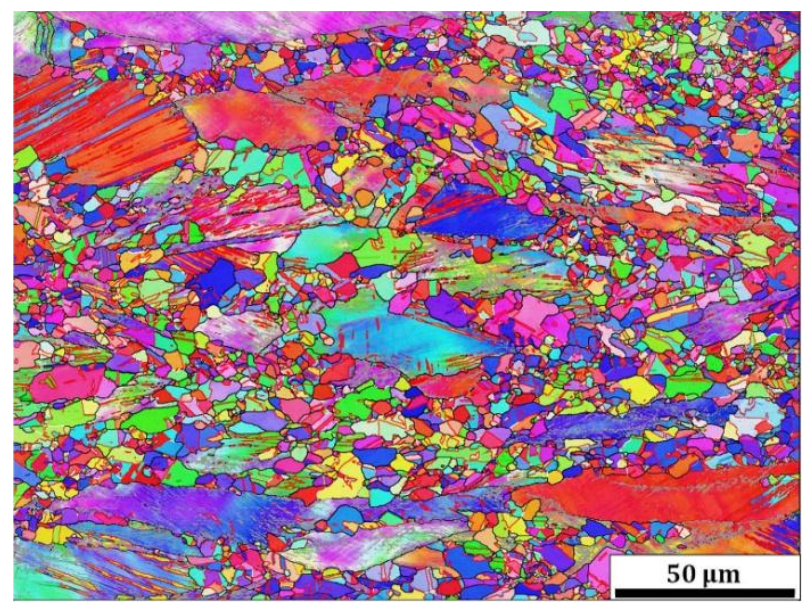

(c)

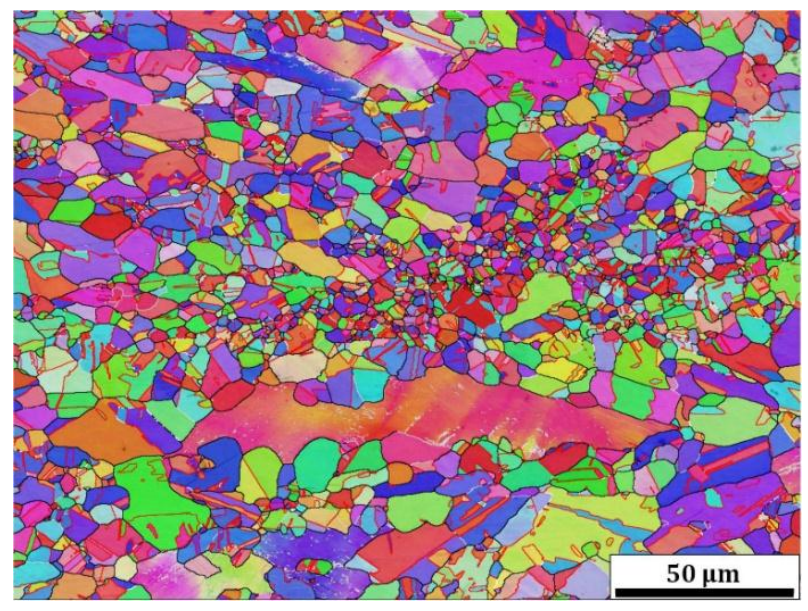

(e)

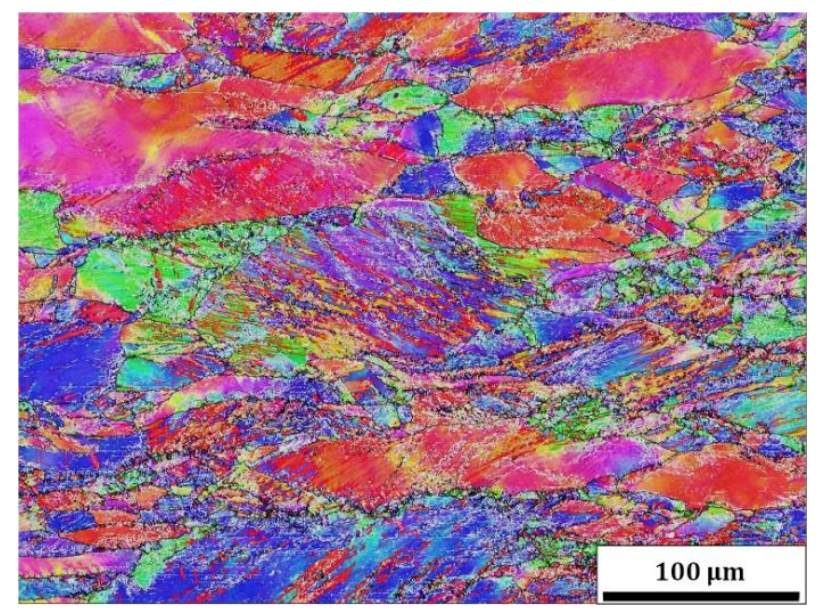

(b)

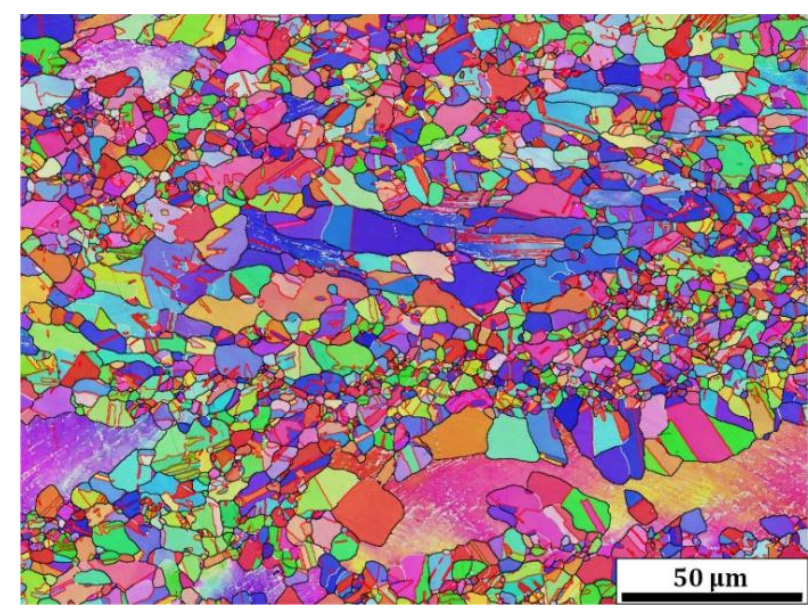

(d)

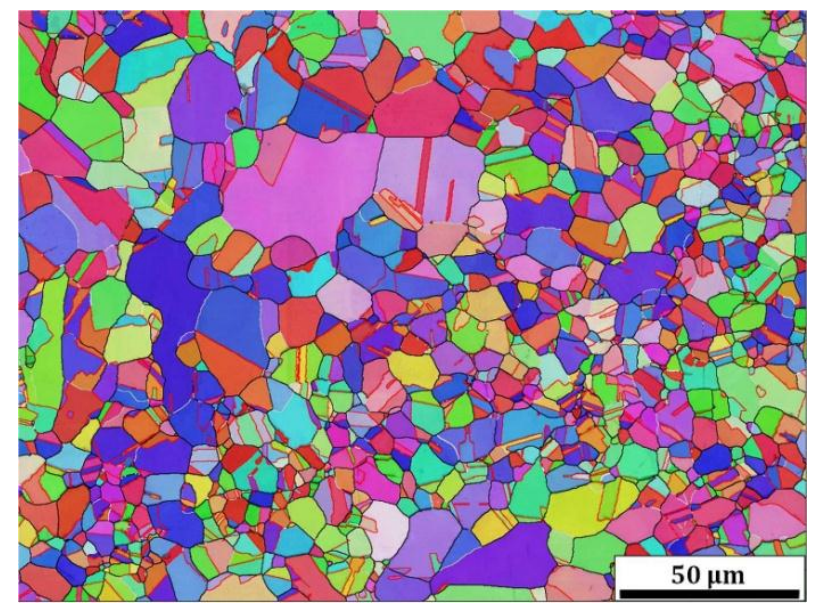

(f)

Figure 2. Representative inverse pole figure (IPF) maps of (a) 42\% cold-rolled, (b) $600^{\circ} \mathrm{C}$ recovered, (c) $700^{\circ} \mathrm{C}$, (d) $750^{\circ} \mathrm{C}$, (e) $775^{\circ} \mathrm{C}$, and (f) $850^{\circ} \mathrm{C}$ partially recrystallised TWIP steel. $\operatorname{LAGBS}\left(2^{\circ} \leq \theta<15^{\circ}\right)=$ grey; HAGBs $\left(15^{\circ} \leq \theta \leq 57.5^{\circ}\right)=$ black; $60^{\circ}\langle 111\rangle \Sigma 3$ $T B s=$ red $; 38.9^{\circ}\langle 101\rangle \Sigma 9 T B s=$ white $; R D=$ horizontal.

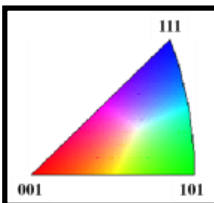




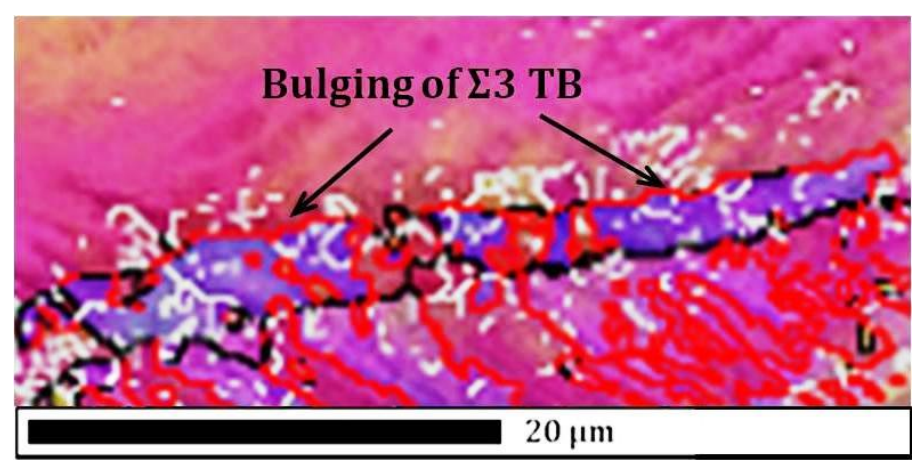

(a)

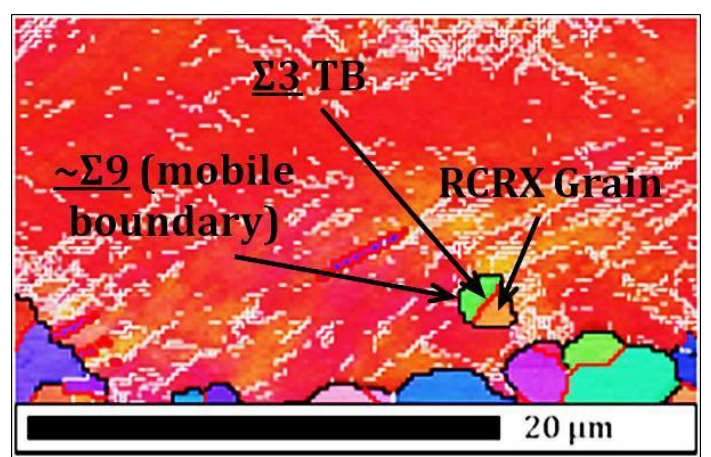

(b)

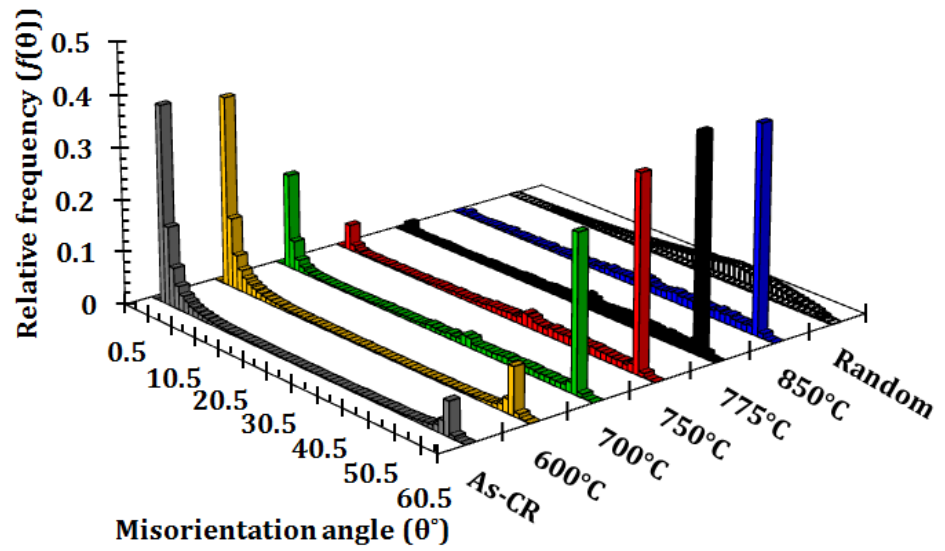

(c)

Figure 3. Magnified views of: (a) annealing twin boundaries ( $\Sigma 3 \mathrm{TBs}$ ) bulging at the boundaries between two grains at $600^{\circ} \mathrm{C}$, and (b) a nucleation event observed at $700^{\circ} \mathrm{C}$. (c) The change in misorientation distribution as a function of the isochronal annealing temperature.

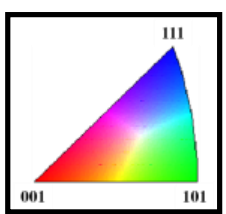




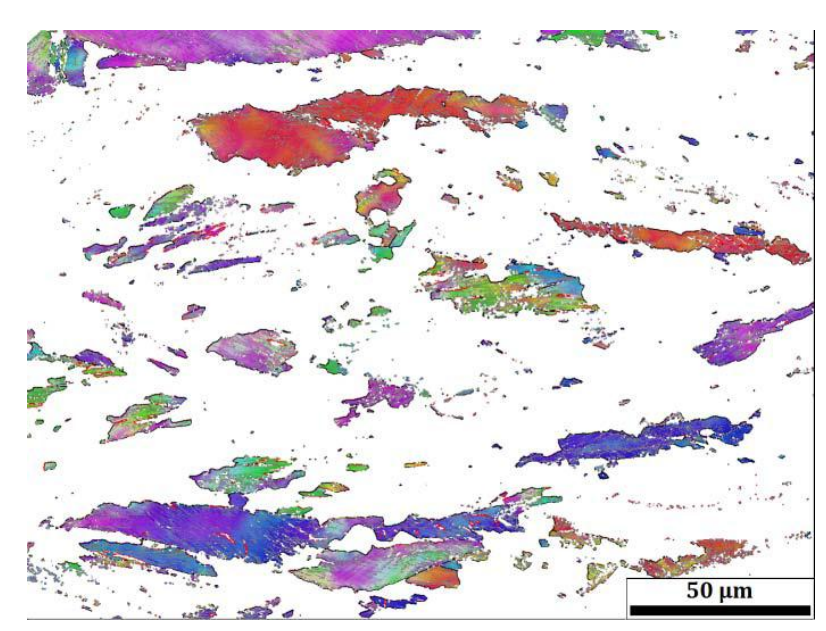

(a)

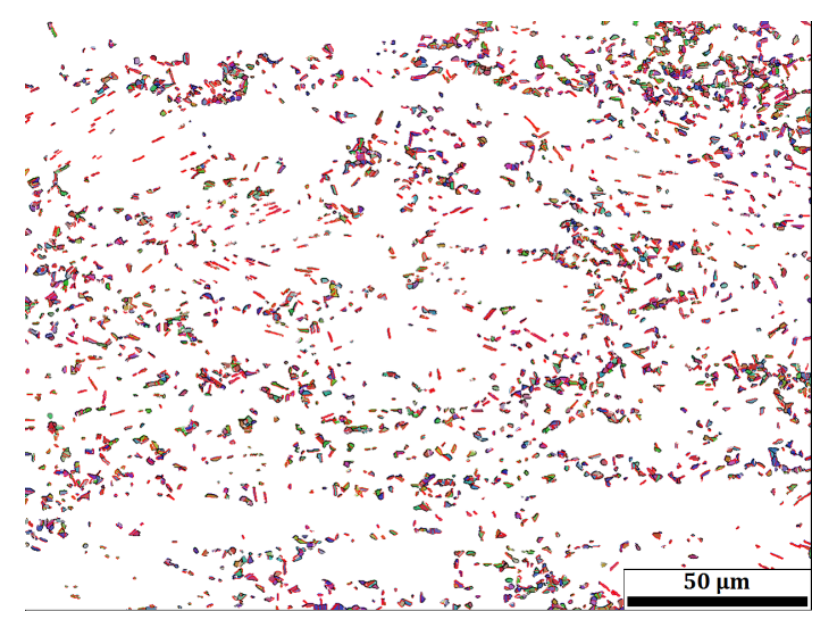

(c)

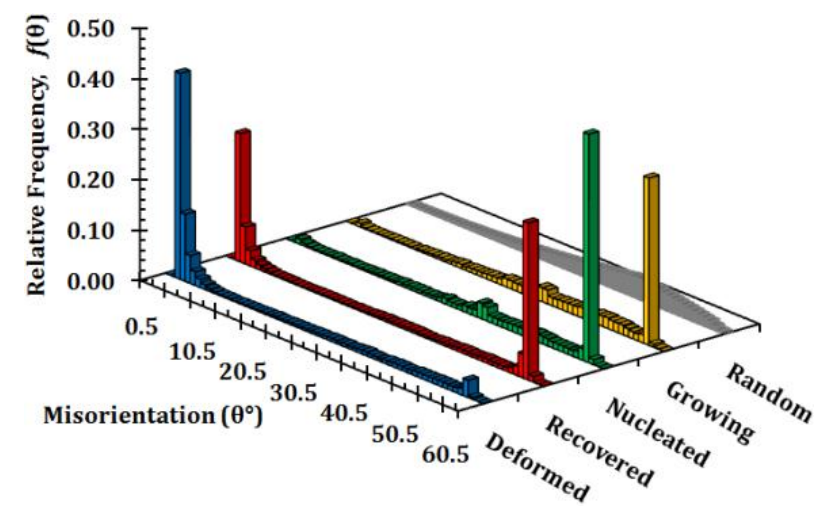

(e)

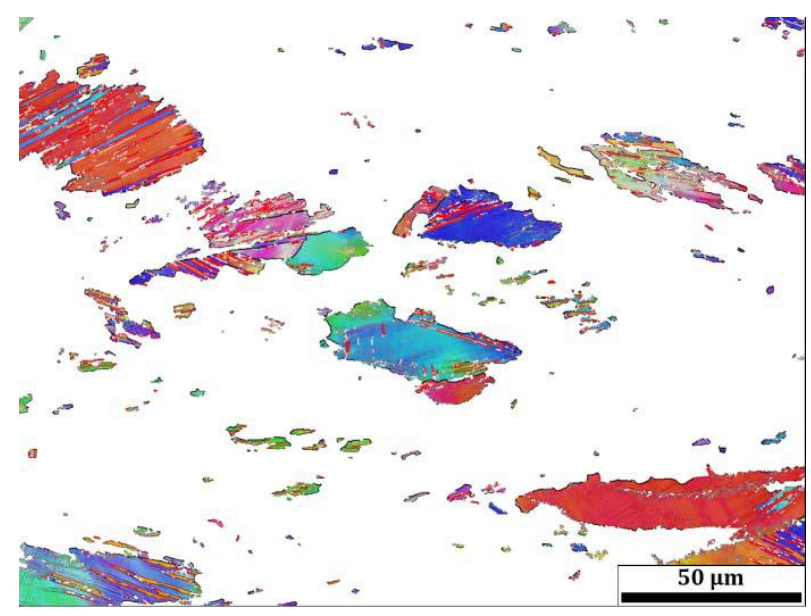

(b)

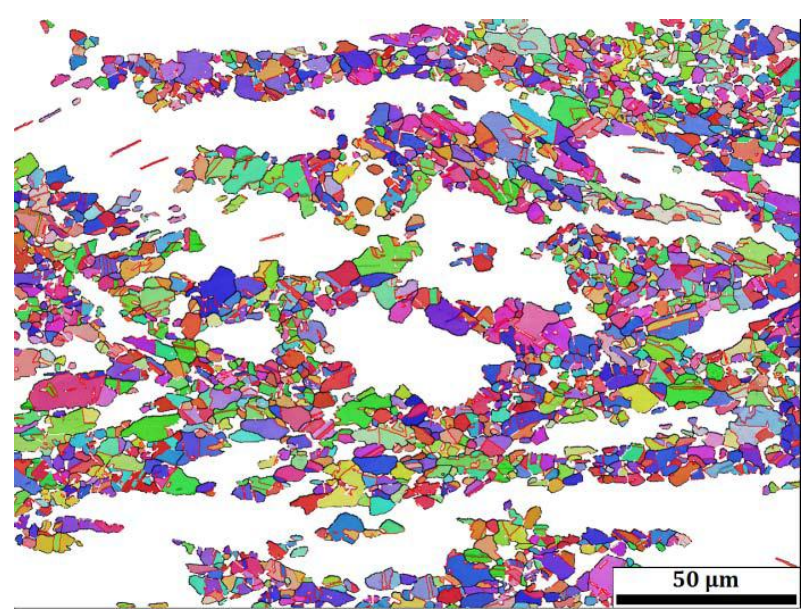

(d)

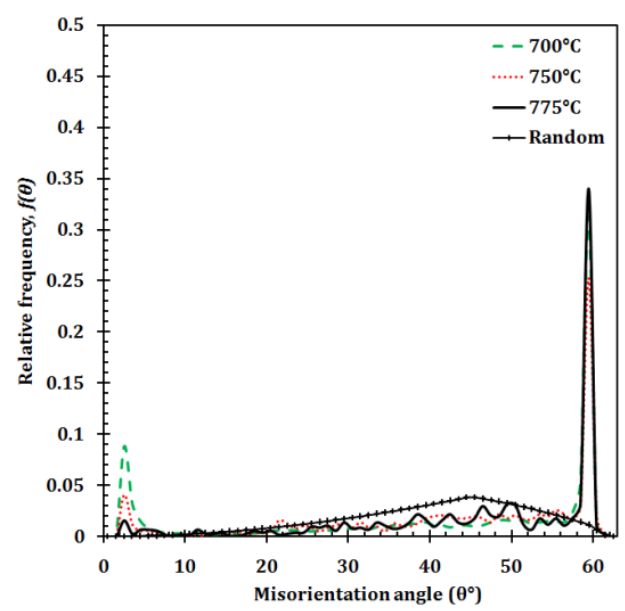

(f)

Figure 4. Inverse pole figure maps of the $700{ }^{\circ} \mathrm{C}$ sample deconstructed into: (a) deformed, (b) recovered, (c) newly nucleated, and (d) growing grain fractions. (e) The misorientation distribution of the various fractions of the $700{ }^{\circ} \mathrm{C}$ sample, and (f) the misorientation distributions at the interface between newly nucleated and

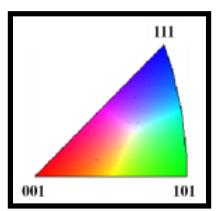
unrecrystallised fractions of the 700,750 and $775^{\circ} \mathrm{C}$ samples. $R D=$ horizontal . 


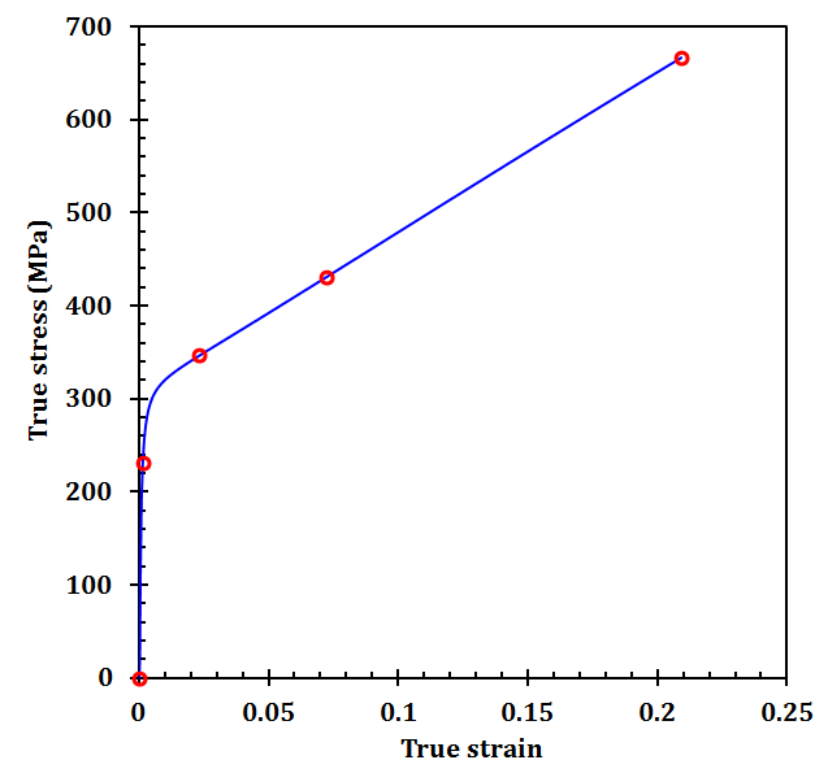

Figure 5. The true stress versus true strain curve of the fully recrystallised $850^{\circ} \mathrm{C}$ sample subjected to uniaxial tension. The red circles indicate the true strains at which the tensile test was interrupted for EBSD mapping. 


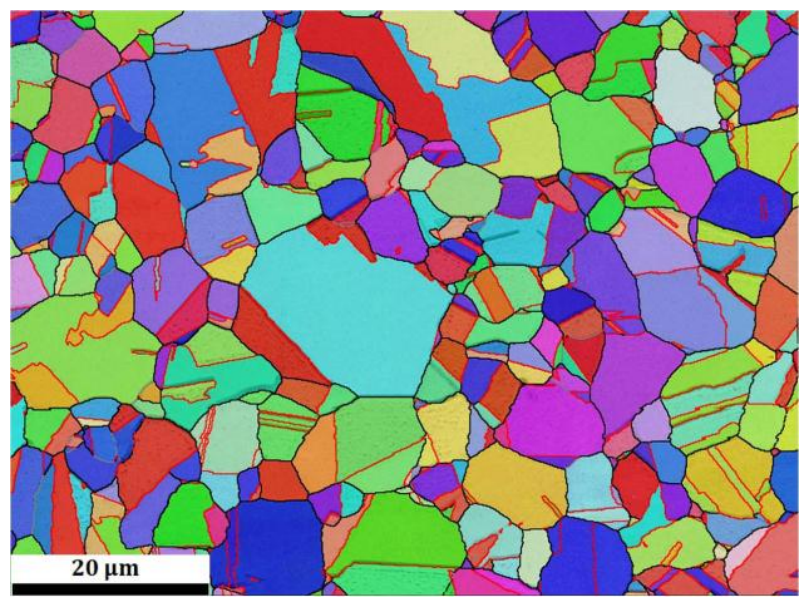

(a)

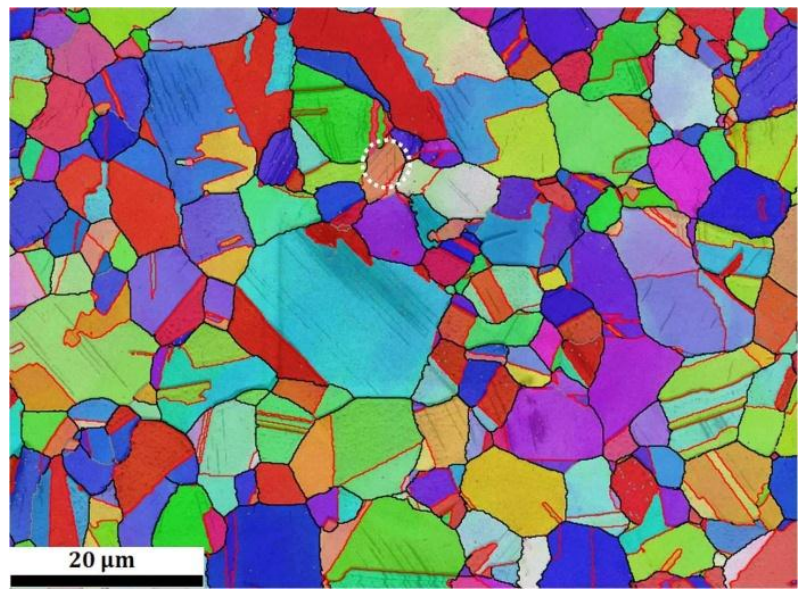

(c)

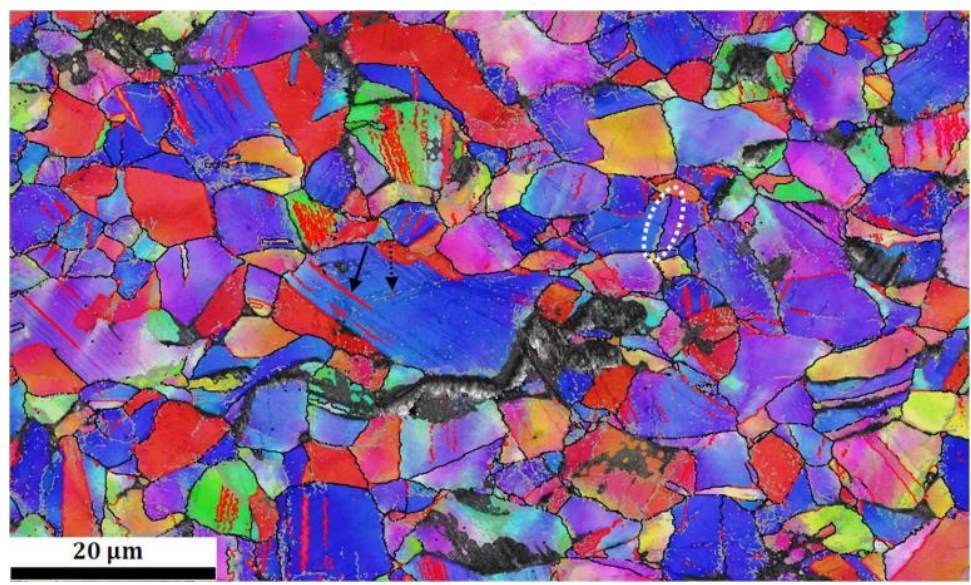

(e)

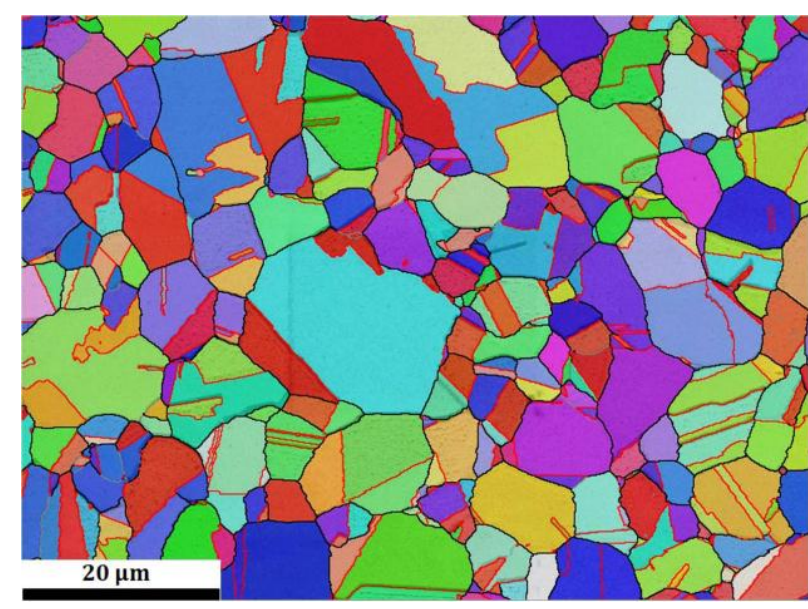

(b)

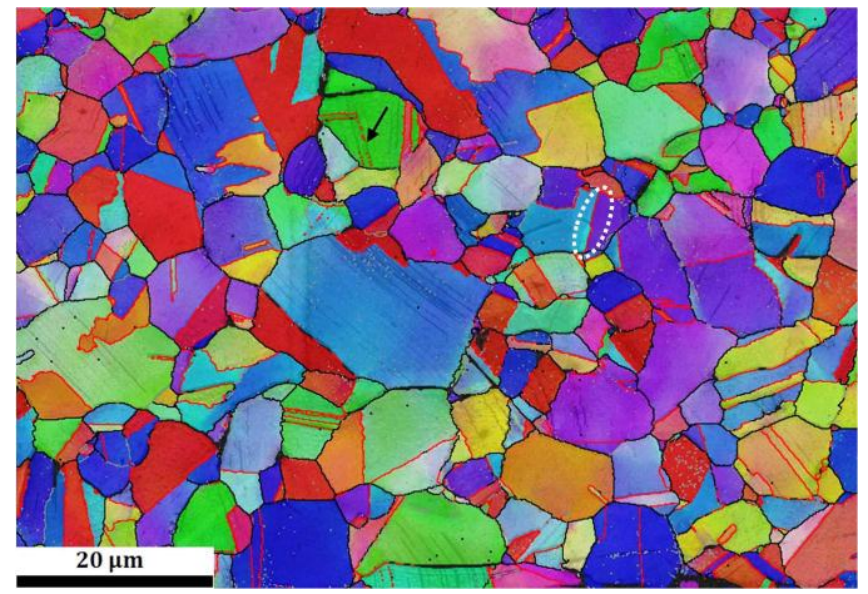

(d)

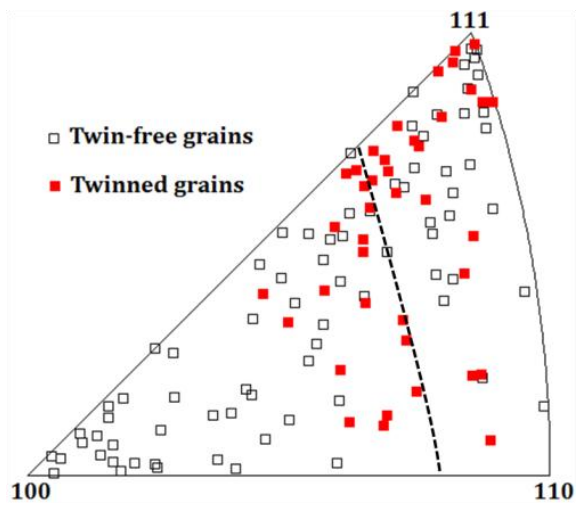

(f)

Figure 6. Inverse pole figure maps at true strains of (a) 0, (b) 0.0014, (c) 0.023, (d) 0.072, and (e) 0.209. (f) Inverse pole figure showing the orientations of twin-free and twinned grains from (e) as clear black and solid red squares, respectively. LAGBs = grey; HAGBs = black; $60^{\circ}\langle 111\rangle \Sigma 3 \mathrm{TBs}=\mathrm{red} ; \mathrm{RD}$ $=$ horizontal . 